\title{
The correlation of learning and study strategies with academic achievement of nursing students
}

\author{
Iman Mohammadi ${ }^{1}$, Hamid Thaghinejad $^{1 *}$, Zainab Suhrabi ${ }^{1}$, Hamed Tavan ${ }^{1}$
}

1. Department of Nursing, Faculty of Nursing and midwifery, Ilam University of Medical Sciences, Ilam, Iran

*Corresponding author:Tel: +98 8412227123 Fax: +98 8412227134

Address: Department of Nursing, Faculty of Nursing and midwifery, Ilam University of medical Sciences, Ilam, Iran

E-mail: hamid2005mordad@yahoo.com

Received; 2015/12/6 revised; 2016/04/22 accepted; 2016/08/7

\begin{abstract}
Introduction: One of the most important problems in student's education is academic failure. Identifying factors that affecting academic achievement and pay attention to these factors is a stride toward success. Students' academic achievement and related factors have priority in education research. This study aimed to determine the relationship between learning study strategies and academic achievement of nursing students in 2013.
\end{abstract}

Materials and methods: This descriptive- analytic study was performed among 85 nursing students of Ilam University of Medical Sciences. By using the learning and study strategies inventory (LASSI), the main three components of study and learning strategies, including items of skill, will and self-regulation were examined. The Pearson correlation was used to measure students' academic achievement correlation with the mentioned above components.

Results: The sample consisted of $50.6 \%$ female and $49.4 \%$ male. The mean grade of nursing students was scored 15.60. Pearson correlation coefficient showed that the three main components of learning strategies and study skills component, respectively skill $(\mathrm{P}=0.001$, $\mathrm{r}=0.349)$, self-regulation $(\mathrm{P}=0.009, \mathrm{r}=0.280)$ and the component of will $(\mathrm{P}=0.045, \mathrm{r}=0.218)$ with student achievement (mean grade of last term) had a positive and significant relationship.

Conclusion: Considering positive and significant correlation between learning and study strategies with academic achievement in nursing students, so, we suggest that students and teachers use these strategies to improve academic achievement and reduce the academic loss of students.

Keywords: Study strategies, Learning, Nursing students, Academic achievement

\section{Introduction}

Psychologists (who engaged in education) have always been interested in learning. They try to identify which processes can be assist learning process (1). Considering learning has a rich and various heritages, there are many learning theories that a number of them emphasize the importance of learning strategies including: double loop learning (Argyris), conversation theory (Pask), and lateral thinking (DeBono). Weinstein (1991) discusses learning strategies in the context of social interaction, an important aspect of Situated Learning Theory (2).Learning strategies refer to methods that students use to learn. This ranges from techniques for improved memory to better studying or test-taking strategies. Students are diverse in age, experiences, level of preparedness, as well as learning styles. Diversity in students' cohorts as well as internationalization increases the demands on nursing academics to fulfill students' needs and preferences motivate and promote 
students' understanding and develop competent curriculum that enhances learning. Information about learning styles and preferences can help faculty become more sensitive to the differences between students, which in turn might help in designing learning experiences that match students' styles. More specifically, considering learning preferences can help individuals begin to understand their needs, and rationalize their choice of teaching strategies suitable for themselves. It can help design a nursing curriculum that might reflect some aspects of the diverse backgrounds of nursing students, which in turn maybe enhance the preparedness of graduates who are competent, confident with appropriate background in knowledge of science in the profession(3). Researchers have varied definitions of learning styles. Vorhaus (2010) defined learning style or preference as how an individual learns, Perceives, interacts with, and responds to the learning environments. Whereas, Felder and Brent (2005) considered learning preferences or Styles as about how the brain works most efficiently to process, comprehend, and learn new information. Varied definitions can point to major Agreement that learning style is an individual's preferred way to learn, a definition that was set early in 1984 by Kocinski. Learning preferences are about the ways that people want to interchange information, and it includes auditory (learning by hearing), visual (learning by seeing), and kinesthetic (learning by doing) (Felder and Brent, 2005; Fleming, 2010) (3). One of the most important method that helps in acquiring information about students 'learning styles is a questionnaire called 'LASSI' developed by Weinstein(4).The Learning and Study Strategies Inventory (LASSI) is a 10-scale, 80-item assessment of students 'awareness about and use of learning and study strategies related to skill, will and self-regulation components of strategic learning. The focus is on both covert and overt thoughts, behaviors, attitudes, motivations and beliefs that relate to successful learning in post-secondary educational and training settings and that can be altered through educational interventions. Research has repeatedly demonstrated that these factors contribute significantly to success in college and that they can be learned or enhanced through educational interventions such as learning strategies and study skills courses. The LASSI is both diagnostic and prescriptive. The LASSI provides standardized scores (percentile score equivalents) and national norms for ten different scales (there is no total score reported because this is a diagnostic instrument). It provides students with a diagnosis of their strengths and weaknesses, compared to other college students, in the areas covered by the ten scales, and it is prescriptive in that it provides feedback about areas where students may be weak and need to improve their knowledge, skills, attitudes, motivations and beliefs (4).

There are eight items on each of the ten scales of the LASSI. These scales are: anxiety, attitude, concentration, information processing, and motivation, selecting main ideas, self-testing, study aids, test strategies, and time management. Each of these scales is primarily related to one of three of the components of strategic learning: skill, will and self-regulation. The conceptual framework of strategic learning underlies each of these components, so there is some overlap and interaction among and within the components and individual scales. However, strategic learners need to know about each of these categories and about how to use information and skills in each of these categories. They also need to know how to pick and choose among the various elements in each category to help them reach specific learning goals and objectives (4). The present study was aimed to assess the correlation between learning and study strategies with academic achievement of nursing students in Ilam University of Medical Sciences. 


\section{Materials and methods}

The present study is a descriptive-analytic study that evaluates academic achievement of nursing students' of the Ilam University of Medical Sciences in the period of January 2013- March 2013 in Ilam, Iran. Though, all nursing students of the university are selected for the study; the students that are studying in the semesters of 7,8 , and 1 were excluded from the study due to their training courses and absence of GPA. All participants agreed to enroll in this study, and they informed that their participation is both voluntary and anonymous, based on Helsinki and Belmont statements. In addition, nursing students are asked to fully complete the questionnaire and a questionnaire is considered invalid if answers were missing for 1 or more questions, and they were omitted.

The required data about learning strategies of nursing students are gathered using second version of the learning and study strategies questionnaire (LASSI), in present research. The questionnaire included 80 items and edited by Weinstein and Palmer in (4). This questionnaire measures three strategies of skill, will and self-regulation using 10 subscales of attitude, motivation, time management, anxiety, concentration, information processing, main idea selection, study aids, self-testing and test strategies. Each scale that includes 8 items is rated on a fivepoint Likert-type scale. In this questionnaire overall score is not our purpose and each scale has its own score. The items are rated using positive and negative scores. For example, half of questions have the score of 1 to 5 and latter half possesses the score of 5 to 1 . So, the score of each scale falls into a range of 8 to 40 . Since the strategies of will and skill consist of three subscales, their scores are ranged from 24 to 120 . Also, selfregulation strategy has four subscale and its scores changes from 32 to 160 .
Correlation coefficient of the questionnaire is reported to be 0.77 to 0.89 by Weinstein (4). In addition, reliability and validity of this questionnaire is confirmed by Salehi et al. (2009) and different Cronbach's coefficient, $\alpha$, is calculated for the scales (0.76 to 0.88) (5). Data analysis is conducted using SPSS (IBM Co, SPSS) version 16.0 and correlation coefficient of Pearson is used to determine association of learning strategies and academic achievement. The one-way ANOVA test is utilized to found the statistical association between demographic variables with the learning strategies subscales.

\section{Results}

The sample consists of 85 nursing students in the school of nursing and midwifery. $80 \%$ of student fully answered to the questionnaire and loss of sample was attributed to 80 items which were fairly much. 33 (38.8\%), 20 (23.6) and 32 (37.6) of nursing students are studying in the third, fourth and fifth semesters, respectively. Age of students is ranged from 19 to $47(21.95 \pm 4.5)$ and the sample consists of 42 boys (49.4\%) and 43 girls $(50.6 \%)$. The average GPA of sample was 15.6 and mean and deviation of study strategies scores are listed in Table 1.

Table 1. Mean and standard deviation scale of learning and study strategies.

\begin{tabular}{ll}
\hline $\begin{array}{l}\text { Scale of learning and study } \\
\text { strategies }\end{array}$ & Mean \pm SD \\
\hline Anxiety & $27.25 \pm 4.30$ \\
Attitude & $26.23 \pm 5.27$ \\
Concentration & $24.29 \pm 4.98$ \\
Information Processing & $25.62 \pm 5.02$ \\
Motivation & $25.35 \pm 4.88$ \\
Self-Testing & $22.01 \pm 4.06$ \\
Selecting Main Ideas & $27.14 \pm 5.21$ \\
Study Aids & $21.96 \pm 4.58$ \\
Time Management & $23.29 \pm 5.01$ \\
Test Strategies & $28.01 \pm 4.75$ \\
\hline
\end{tabular}

The high average score of students was related to the test strategy, anxiety, main idea selection and attitude subscales, respectively and the lowest score is obtained for the study aids subscale. In 
addition, motivation, concentration, selftesting and time management are received the lowest scores among other subscales, respectively. Results of correlation coefficient between learning, study strategies and GPA are given in Table 2.

Table 2. The correlation between academic achievement with scale of learning and study strategies.

\begin{tabular}{lcc}
\hline $\begin{array}{l}\text { Scale of learning and study } \\
\text { strategies }\end{array}$ & $\mathrm{r}$ & $\mathrm{P}$ value \\
\hline Anxiety & 0.140 & 0.20 \\
Attitude & 0.054 & 0.62 \\
Concentration & 0.140 & 0.04 \\
Information Processing & 0.222 & 0.15 \\
Motivation & 0.165 & 0.01 \\
Self-Testing & 0.267 & 0.06 \\
Selecting Main Ideas & 0.198 & 0.00 \\
Study Aids & 0.310 & 0.63 \\
Time Management & 0.052 & 0.00 \\
Test Strategies & 0.342 & 0.00 \\
\hline
\end{tabular}

An association is found between concentration $\quad(\mathrm{P}=0.041)$, motivation $(\mathrm{P}=0.014)$, main idea selection $(\mathrm{P}=0.004)$, time management $(\mathrm{P}=0.001)$ and test strategies $\quad(\mathrm{P}=0.000)$. Moreover, a significant relationship between three main scales of study and learning strategies and academic achievement is observed (Table 3). It is worthwhile that criteria of meaningful statistics is considered when $\mathrm{P}<0.05$ satisfies.

Table 3. The correlation between academic achievement with three main components of learning and study strategies.

\begin{tabular}{lcc}
\hline Learning and Study Strategies & $\mathrm{r}$ & $\mathrm{P}$ value \\
\hline Sill & 0.34 & 0.00 \\
Will & 0.218 & 0.04 \\
Self-regulation & 0.280 & 0.00 \\
\hline
\end{tabular}

Variance analysis showed that an association between skill, gender $(\mathrm{P}=0.005)$ and academic grade of students $(\mathrm{P}=0.001)$ is existed. The strategies of will versus gender $(\mathrm{P}=0.001)$ and selfregulation versus academic grade $(\mathrm{P}=0.005)$ are shown a relationship. The subscales of skill also showed an association with demographic date of students. For example, the information processing with academic grade
$(\mathrm{P}=0.006)$, main idea selection with gender $(\mathrm{P}=0.015)$, main idea with academic grade $(\mathrm{P}=0.003)$ and test strategies with age $(\mathrm{P}=0.022)$ and gender $(\mathrm{P}=0.001)$ of participants are illustrated an association. In the subscales of will, a relationship is found for attitude with gender of nursing students $\quad(\mathrm{P}=0.003) . \quad$ Eventually, concentration versus academic grade $(\mathrm{P}=0.008)$, self- testing versus academic grade $(\mathrm{P}=0.008)$ and time management with gender are indicated a relationship, in the view of self-regulation strategy.

\section{Discussions}

Yaghob Khani Ghiasvand (2010) reported that there is a relationship between learning strategies and academic achievement. In present study, a significant and positive association between the strategies of skill, will and self-regulation with academic achievement is obtained which is in agreement with that of Yaghob Khani Ghiasvand (2010) (1). Atarodi is also shown that study and learning strategies is in relation with academic achievement and self-testing, information processing, test strategies and anxiety have a direct impact on GPA of students (6).

Saheb Zamani and Zirak are also indicated that there is an inverse relationship between study and learning strategies with anxiety. Furthermore, our finding showed that there is an association between concentration and motivation subscales versus GPA of students. In the case of Saheb Zamani and Zirak it is seen that mean scores of attitude, concentration and motivation are shown an association versus GPA of students (7). Hence, our results are in agreement with the case of Saheb Zamani and Zirak. Feizipour is reported that girl students possess higher motive than boys (8) which is in contrary with our results due to difference in the applied assay tools. It is noted that Feizipour performed his research using Herments motive achievement questionnaire. Jahromi is investigated that 
academic achievement is achievable using the knowledge of time management (9). In present contribution, an association between time management and academic achievement of students is observed which is in agreement with our results. Jahansir is shown that although a significant relationship between short time planning and attitude with academic achievement is existed (10); no association is observed between long time planning with academic achievement .

In our research, it is found that there is an association between skill subscales, selfregulation, information processing, main idea selection, concentration and selftesting with academic grade of students. However, our results are not consistent with that of KhadivZadeh study (11). In the case of Khadiv Zadeh (2004) no association is obtained for scales of learning and study strategies with academic grade. In present research, higher score of study strategies is obtained for anxiety, main idea selection and attitude subscales, respectively which are in agreement with the study of KhadivZadeh. Khaled (2010) is shown that academic achievement of girl students is more than boy students. In this study, the same results is found $(\mathrm{P}=0.001)$. Khaled (2010) also investigated that among the students with academic motivation, gender of students adjust learning strategies in the benefits of girls (12) in which no difference is obtained between motivation of boys and girls, in this study. In the case of Roushan $\neg$ Milani (13) a correlation

\section{References}

1. Yaghobkhani Ghiasvand M. Relationship between learning strategies and academic achievement; based on information processing approach. Proc Soc Behav Sci. 2010; 5(3):1033-6.

2. Bickerdike A, O'Deasmhunaigh C, O'Flynn S, O'Tuathaigh C. Learning between GPA and academic motivation of students is found which is consistent with present study. Salahi et al (5) showed that a correlation is observed between academic achievement of students with study and learning strategies.

Study and learning strategies have a critical impact on amount of students learning. However, these strategies are not used by students which cause reduction in learning level and academic failure between students (6). Serin et al. (14) investigated that a correlation is existed between subscales of motivation, anxiety, main idea selection and study aids among men and women, in Greece.

A significant association between the scales of skill will and self- regulation with academic achievement of students is found, in this study. As, academic achievement has an impact on learning strategies; students are able to improve their learning using learning strategies. So, students and instructors are encouraged to use learning strategies questionnaire and Weinstein learning as an efficient tools to determine any kind of weakness and strength in their learning .

\section{Acknowledgments}

The authors acknowledge with grateful appreciation the kindly assistance and support provided by the Research deputy at the Ilam University of Medical Sciences. We also thank students who agreed to participate in this study. 
teaching. Nurse Educ Today. 2013; 33(12):1546-9.

4. Weinstein CE, Palmer D. Learning and Study Strategies Inventory Second Edition. 2002.

5. Salehi M, Enayati T. Between the main components of learning and study strategies and academic achievement of students of Islamic Azad University, Mazandaran. New approach Journal of Educ Manag. 2009; 2(3):145-62.

6. Hosseini L, Atardy A, Mqymyan M. Evaluation of the use of learning and study strategies. Knowledge Horizon. 2005; 11(1):53-60.

7. Saheb Alzamani M, Zirak A. Students'learning and study strategies in Isfahan University of medical sciences and their relationship with test anxiety. Iran J Med Educ. 2011; 11(1):58-68.

8. Giofrè D, Mammarella IC, Cornoldi C. The relationship among geometry, working memory, and intelligence in children. J Exp Child Psychol. 2014; 123:112-28.

9. Friedman CP, Donaldson KM, Vantsevich AV. Educating medical students in the era of ubiquitous information. Med Teach. 2016; 38(5):504-9.
10. Jhansyr S, Salhzadh K, Vsaqy H, Mousavi Far I. effect of time management on students' progress of Islamic azad university of Maragheh. Res Sci Educ. 2008; 21(16):97-114.

11. Khadivzadeh T, Saif A, Valayy N. Learning and study strategies, Mashhad university of medical sciences and their relationship with their academic and personal characteristics. Educ Iran J Med Sci. 2004; 4(12):53-61.

12. Dalen JD. Gender differences in the relationship between school problems, school class context and psychological distress: results from the YoungHUNT 3 study. Soc Psychiatry Psychiatr Epidemiol. 2014; 49(2):18391.

13. Chew BH, Md Zain A, Hassan F. The relationship between the social management of emotional intelligence and academic performance among medical students. Psychol Health Med. 2015; 20(2):198-204.

14. Serin O, Serin NB, !ahin FSl. Factors affecting the learning and studying strategies, and locus of control of the trainee teachers. Proc Soc Behav Sci. 2009; 1(1):1127-36. 